\title{
Edukasi Pencegahan Diabetes Melitus Sejak Dini: Pengabdian Masyarakat di Pesantren Tahfidh Qur'an Nyamplungsari Pemalang Jawa Tengah
}

\author{
1*Isyti'aroh Isyti'aroh, ${ }^{1}$ Dwi Fijianto, ${ }^{1}$ Alya Fara, ${ }^{1}$ Syamilla Nur Cahya \\ ${ }^{1}$ Universitas Muhammadiyah Pekajangan Pekalongan \\ *Penulis korespondensi, email: isytiaroh74@gmail.com
}

(Received: 20 September 2021/Accepted: 18 November 2021/Published: 31 January 2022)

\begin{abstract}
Abstrak
Salah satu faktor pencetus penyakit diabetes melitus adalah pola hidup yang tidak sehat. Oleh karena itu pola hidup sehat harus diterapkan sejak dini agar terhindar dari penyakit diabetes melitus. Tujuan pengabdian masyarakat ini adalah memberikan pemahaman pentingnya pencegahan diabetes melitus sejak dini melalui edukasi pola hidup sehat. Metode pengabdian masyarakat melalui edukasi dengan sasaran santri dan pengelola Pondok Pesantren Tahfidh Qur'an Al Fath Nyamplungsari Pemalang sejumlah 31 peserta. Edukasi meliputi pengertian diabetes melitus, penyebab dan faktor resiko, tanda gejala, jenis diabetes melitus, proses terjadinya penyakit, dan bagaimana pencegahan diabetes militus sejak dini. Metode edukasi dengan ceramah, diskusi, dan demonstrasi. Penilaian pemahaman dilakukan melalui tes tertulis sebelum dan sesudah edukasi. Hasil evaluasi menunjukkan ada peningkatan rata-rata nilai pemahaman dari 68,4 menjadi 83,2 (rentang nilai 10-100). Evaluasi proses menunjukkan keaktifan dari peserta edukasi dari awal sampa akhir kegiatan. Simpulan dari pengabdian masyarakat ini adalah edukasi dapat meningkatkan pemahaman tentang pencegahan diabetes melitus sejak dini.Disarankan agar edukasi pencegahan diabetes melitus dapat dilakukan sejak dini di sekolah tingkat dasar maupun menengah.
\end{abstract}

Kata Kunci: diabetes melitus, edukasi, pola hidup sehat

\begin{abstract}
One of the contributing factors diabetes melitus disease is an unhealthy lifestyle. Therefore, a healthy lifestyle must be applied from an early age to avoid diabetes mellitus. The aim of this community service is to provide an understanding of the prevention of diabetes mellitus from an early age with education on healthy lifestyles. The method is given education with the target of students and managers of the Al Fath Nyamplungsari Islamic boarding school in Pemalang Centre Java. The total participants were 31 participants. The topic of education includes definition of diabetes mellitus, causes and risk factors, signs of symptoms, types of diabetes mellitus, disease process, and how to prevent diabetes mellitus from an early age. Educational methods with lectures, discussions, and demonstrations. Evaluations of understanding by tests before and after education. The results of the evaluation increased the mean of understanding diabetes mellitus from 68.4 to 83.2 (range of values 10-100). And based on participation during activities, the participants follow from beginning to the end the activity. The conclusion from this community service is that education can increase understanding of diabetes mellitus prevention from an early age. It is recommended that diabetes mellitus prevention education can be carried out from an early age in primary and secondary schools.
\end{abstract}

Keywords : Diabetes Mellitus, Education, healthy lifestyle 


\section{Pendahuluan}

Salah satu tempat pendidikan formal yang ada di Indonesia adalah pondok pesantren. Sistem pendidikan di pesantren mengintegrasikan tempat tinggal santri sebagai peserta didik dengan tempat pendidikan terutama pendidikan agama. Konsekuensi sistem pendidikan pondok pesantren menuntut kemandirian santri dalam menjalani pola hidup sehat dan pengawasan dari pengelola pesantren agar santri dapat tumbuh dan berkembang menjadi generasi yang sehat.

Tantangan yang dihadapi adalah keterbatasan pemahaman tentang bagaimana menjalani pola hidup sehat agar terhindar dari penyakit infeksi maupun non infeksi. Salah satu penyakit non infeksi yang perlu dilakukan pencegahan adalah penyakit diabetes melitus (DM). Alasannya adalah banyaknya kejadian penyakit DM di Indonesia.

Pusat Data dan Informasi Kementrian Kesehatan Republik Indonesia (Pusdatin Kemenkes RI), memperkirakan di Indonesia pada tahun 2030 ada sekitar 21,3 juta jiwa yang menderita DM (Pusdatin RI, 2018). Banyaknya kasus DM di Indonesia juga disebabkan karena peningkatan kasus DM pada anak. Data dari Pusdating Kemenkes RI (2018) mencatat kasus DM pada anak sejumlah $0.004 \%$ pada anak umur 5 - 14 tahun.Data yang dipaparkan Ikatan Dokter Anak Indonesia (IDAI) (2017) pada anakusia 15-25 tahun angka kejadiannya $0.05 \%$ dari seluruh penduduk Indonesia.

DM pada anak diklasifikasikan menjadi 2 yaitu tipe 1 dan tipe 2 . Tipe 1 sering ditemukan pada anak. DM jenis ini mempunyai ketergantungan insulin mutlak. Pada DM tipe 2 biasanya terjadi karena faktor gaya hidup, pola makan, stressor dan jarangnya olahraga (IDAI, 2017).

Menilik faktor penyebab terjadinya DM tipe 2, maka perlu pencegahan dilakukan sedini mungkin. Salah satu cara yang dilakukan adalah dengan edukasi. Hal ini sesuai dengan penelitian bahwa edukasi dapat berperan penting dalam peningkatan pengetahuan (Wahyuni, Prayitno \& Yosi, 2019). Hasil pengabdian masyarakat tentang edukasi dan deteksi dini diabetes melitus sebagai upaya mengurangi prevalensi dan resiko penyakit degeneratif juga menunjukkan adanya peningkatan pengetahuan peserta edukasi (Muliasari, Hamdin, Ananto \& Ihsan, 2019).

Lembaga pendidikan sebagai bagian penting dalam mencerdaskan kehidupan bangsa harus menjadi salah satu pilar yang dilibatkan dalam pencegahan DM secara dini pada anak. Pondok Pesantren Nyamplungsari sebagai salah satu lembaga pendidikan menjadi salah satu tempat yang dapat dijadikan mitra dalam pengabdian masyarakat ini. Diharapkan pengabdian masyarakat ini dapat meningkatkan pengetahuan atau pemahaman santri tentang pencegahan DM sejak dini sehingga tumbuh kembangnya optimal dan mampu belajar dengan baik dan mengoptimalkan produktifitasnya di masa selanjutnya.

\section{Metode}

Metode pengabdian masyarakat melalui tahapan persiapan, pelaksanaan, evaluasi dan rencana tindak lanjut. Uraian tahapan pengabdian masyarakat sebagai berikut :

\subsection{Persiapan}

Tahap persiapan dilakukan dengan survey ke pondok pesantren tentang jumlah santri, bagaimana kondisi santri dan bagaimana pola makan santri dan jajanan yang ada di lokasi pondok.Tahapan ini juga mengkaji syarat administrasi pelaksanaan pengabdian masyarakat.

\subsection{Pelaksanaan}

Tahap pelaksanaan dilakukan edukasi dengan sasaran santri dan pengelola Pondok Pesantren Tahfidh Qur'an Nyamplungsari Petarukan Pemalang sejumlah 31 peserta. Edukasi meliputi pengertian diabetes melitus, penyebab dan faktor resiko, tanda gejala, jenis diabetes 
melitus, proses terjadinya penyakit dan pencegahan diabetes militus sejak dini. Metode edukasi dengan ceramah, diskusi atau tanya jawab dan demonstrasi. Demonstrasi terutama dilakukan pada proses cara menjaga kebersihan dan kebugaran tubuh. Penilaian pemahaman dilakukan melalui tes tertulis sebelum dan sesudah edukasi. Tes tertulis berupa soal pilihan ganda yang disusun oleh tim pengabdian masyarakat. Rentang penilian 10-100.

Tahapan pelaksanaan dimulai dengan pre test, kemudian pemaparan materi menggunakan media LCD dan alat demonstrasi berupa handrub dan masker. Handrub dan masker digunakan untuk demonstrasi cara cuci tangan dan pencegahan penyakit menular terutama Covid19 karena pelaksanaan pengabdian masyarakat dilakukan saat pandemi Covid-19 dan penderita DM rentan terhadap infeksi. Metode edukasi dengan ceramah, tanya jawab dan demonstrasi.

\subsection{Evaluasi}

Evaluasi kegiatan pengabdian masyarakat dilakukan dengan post test. Post test untuk mengukur pemahaman setelah dilakukan edukasi. Nilai post test kemudian dibandingkan dengan nilai pre test.

\section{Hasil dan Pembahasan}

Pengabdian masyarakat dilakukan melalui tahapan persiapan, pelaksanaan dan evaluasi. Uraian pan adalah sebagai berikut :

\subsection{Tahapan Persiapan}

Tahapan persiapan meliputi kegiatan persiapan administrasi dengan pembuatan surat ijin dan proposal, persamaan persepsi antara tim dengan pengelola pondok beserta pembagian tugas dengan mitra. Setelah tahap persiapan selesai maka pengabdian masyarakat dilaksanakan.

\subsection{Tahap Pelaksanaan}

Pelaksanaan pengabdian masyarakat berjalan baik dan lancar. Edukasi dilakukan secara bergantian bersama tim dosen lain dan mahasiswa. Dokumentasi kegiatan pengabdian masyarakat dapat dilihat di Gambar 1 dan 2.

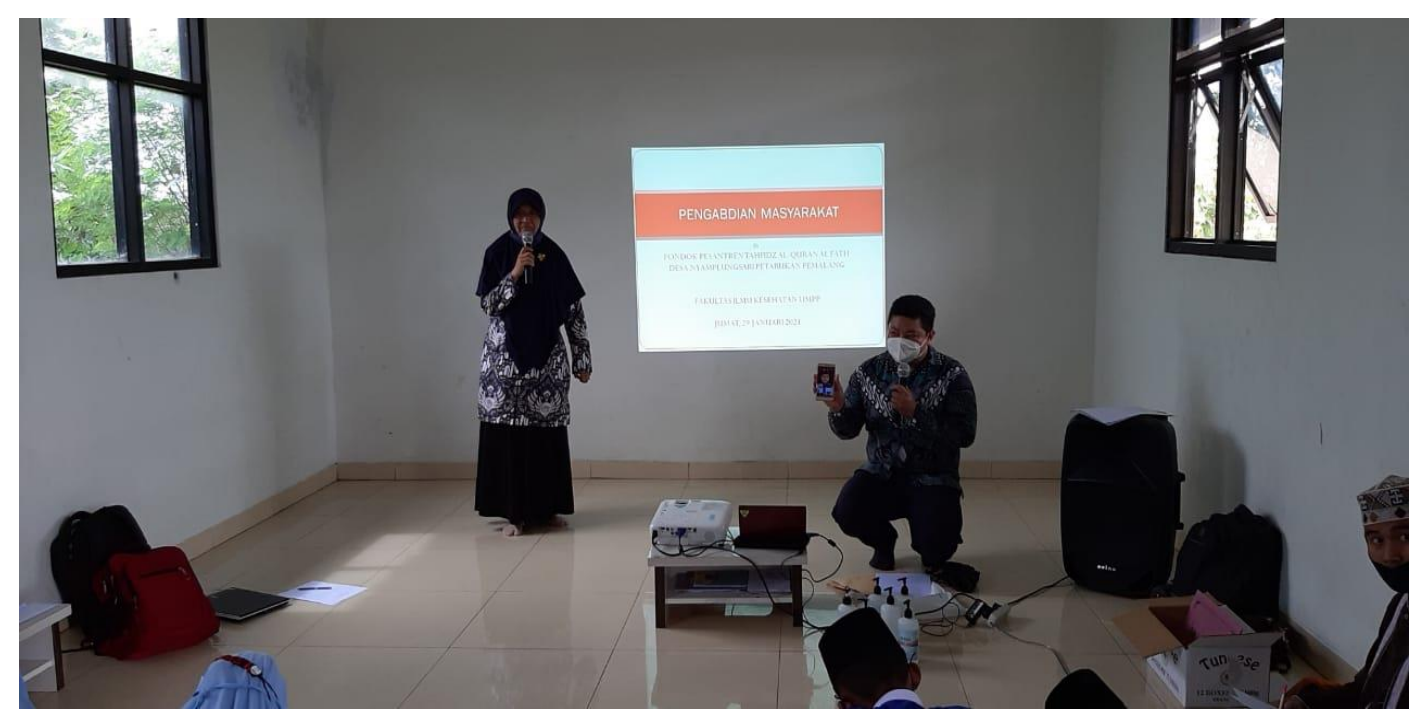

Gambar 1. Pembukaan Pengabdian Masyarakat 


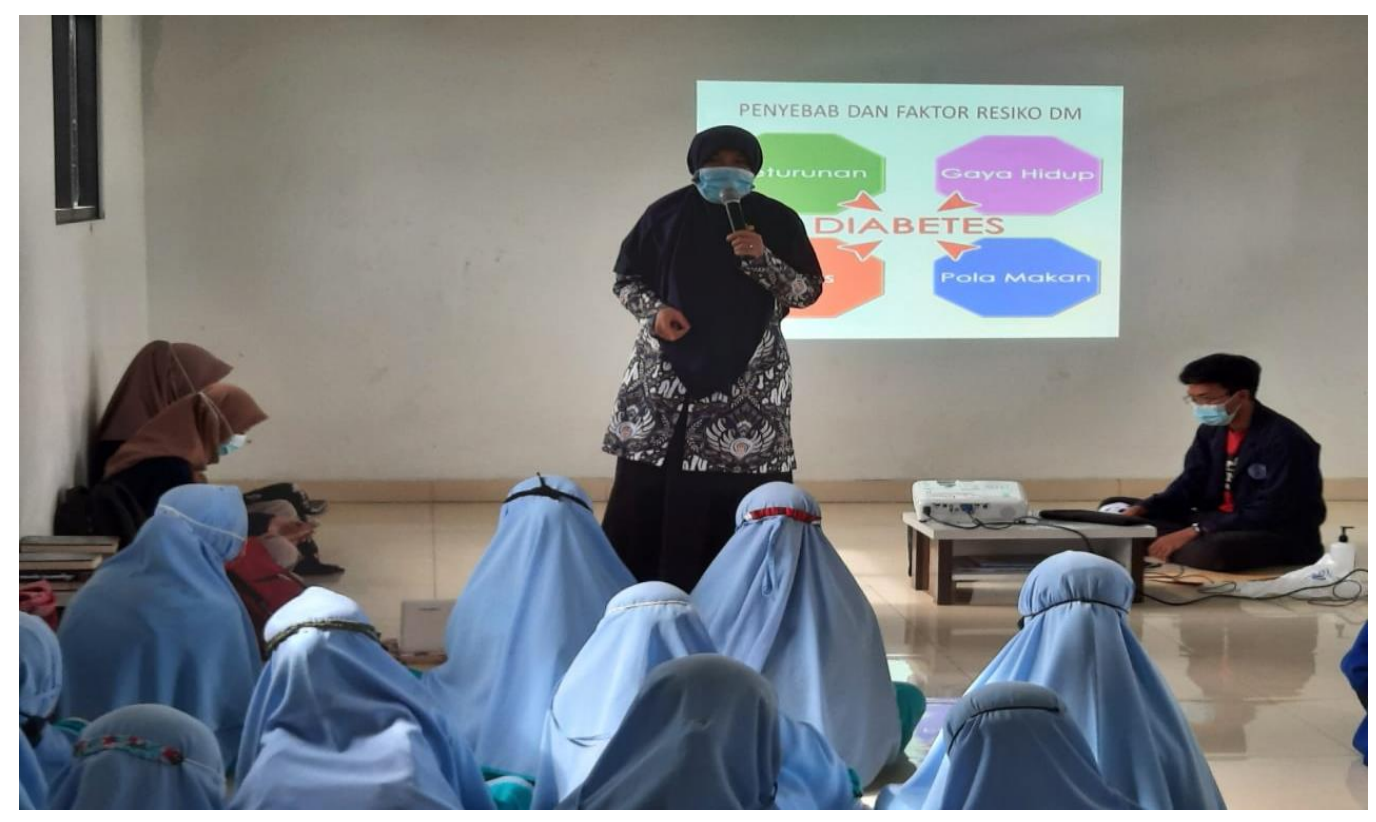

Gambar 2. Pelaksanaan Edukasi

Hasil pengabdian masyarakat yang berhubungan dengan pemahaman peserta terjadi kenaikan rata-rata nilai post test dibandingkan dengan pre test. Tabel 1 menggambarkan kenaikan penilaian pemahaman peserta.

Tabel 1. Rata-Rata Nilai Pemahaman Sebelum dan Sesudah Edukasi

\begin{tabular}{cccc}
\hline \multirow{2}{*}{ Hasil Penilaian } & \multicolumn{3}{c}{ Nilai Rata-Rata } \\
\cline { 2 - 4 } & Pretest & Postest & Peningkatan Nilai \\
\hline $\begin{array}{c}\text { Tingkat } \\
\text { Pemahaman }\end{array}$ & 68,4 & 83,2 & 14,8 \\
\hline
\end{tabular}

Tabel 1 menggambarkan ada kenaikan sebesar 14,8 poin hasil penilaian pemahaman terkait edukasi pencegahan DM sejak dini. Kenaikan ini sangat baik karena jika dikatagorikan maka tingat pemahaman bergeser dari nilai cukup ke nilai baik.

Tabel 1 diatas menunjukkan hasil perbedaan rata-rata sebelum dan sesudah diberikan edukasi, dengan kenaikan nilai pemahaman sebesar 14,8 point. Hasil ini sejalan dengan pengabdian masyarakat yang dilakukan oleh Saryanti dan Nugraheni (2019) tentang Peningkatan Pengetahuan Masyarakat Tentang Diabetes Melitus di Kabupaten Sukoharjo Jawa Tengah dengan metode pemberian edukasi atau penyuluhan. Hasil penyuluhan menunjukkan terdapat peningkatan pemahaman masyarakat mengenai diabetes melitus dengan katagori baik yaitu dari $67,83 \%$ menjadi 90,43\%. Demikian pula yang dilakukan oleh Rosyid, Hudiawati \& Kristinawati (2019) dalam program pengabdian masyarakat melalui pendidikan kesehatan. Hasil kegiatan pendidikan kesehatan dengan menggunakan model ceramah dan demonstrasi mempunyaiefek positif pada pengetahuan, upaya pencegahan dan sikap peserta tentang DM. Sedangkan berdasarkan hasil penelitian, Fajriyah, Aktifah \& Mugiyanto (2020) tentang Paket Edukasi dan Deteksi Dini Meningkatkan Perilaku Perawatan Kaki Diabetisi di Puskesmas Kabupaten Pekalongan menunjukkan hasil edukasi dan deteksi dini DM mempunyai efek terhadap perilaku perawatan kaki pasien dengan $\mathrm{p}=0,001$.

Perubahan perilaku sehat adalah tujuan yang ingin dicapai setelah dilakukan edukasi karena edukasi bukan hanya transfer pemahaman. Hal ini sesuai dengan yang diungkapkan Sari (2013) bahwa perubahan perilaku menjadi sehat melalui pendidikan kesehatan bukan sekedar 
memindahkan ilmu pengetahuan dan sikap dari pendidik, tetapi bagaimana peserta didik mampu berperilaku dengan menselaraskan lingkungan, perilaku dan manusia agar seimbang. Penyuluhan atau edukasi dapat diartikan sebagai upaya yang dilakukan secara sengaja dan terencana agar ada perubahan perilaku individu, kelompok atau masyarakat agar tahu, mau, dan mampu memecahkan permasalahan yang dihadapi. Tujuan penyuluhan atau edukasi adalah meningkatkan kualitas dan martabat hidup dan kehidupan manusia (Amanah, 2007).

Faktor pendukung keberhasilan pendidikan kesehatan diantaranya karena penggunaan media dan metode pembelajaran yang disesuaikan dengan karakteristik peserta pengabdian masyarakat. Media pembelajaran yang digunakan adalah powerpoint, video, dan media untuk demonstrasi cuci tangan. Penggunaan media pembelajaran disesuaikan dengan tujuan dan sasaran pembelajaran. Menurut Miftah (2013) media sebagai bagian tak terpisahkan dari pembelajaran, perlu mendapatkan perhatian bagi para pendidik. Media pembelajaran penting untuk memfasilitasi peserta didik (pembelajar). Hadirnya media dalam proses pembelajaran sangat membantu pembelajar lebih memahami hal yang dipelajari.

Supriyono (2018) juga menjelaskan bagaimana memilih dan menggunakan media yang menarik, efektif dan efisien.Setidaknya ada 5 hal yang harus diperhatikan dalam pemilihan media. Kelima hal yang harus diperhatikan dalam pemilihan media adalah (1) media harus dibuat sesederhana mungkin agar jelas dan mudah dipahami oleh peserta didik; (2) media dirancang menyesuaikan dengan pokok bahasan yang akan disampaikan; (3) media dirancang tidak membingungkandan tidak terlalu rumit; (4) tanpa mengurangi makna dan fungsi media, bahan untuk membuat media sederhana mungkin dan mudah didapat, (5) media pembelajaran dapat dirancang berupa model, gambar, bagan berstruktur, dan lainnya dengan bahan yang murah dan mudah didapat (Supriyono 2018). Pada pelaksanaan pengabdian masyarakat di Pondok Pesantren Tahfidh Qur'an Nyamplungsari Petarukan Pemalang kelima hal tersebut sudah dilakukan. Media yang digunakan berupa powerpoint, leaflet, LCD, alat demonstrasi cuci tangan dan video edukasi.

Edukasi yang dilakukan pada santri pondok pesantren Al Fath juga menggunakan metode pembelajaran yang interaktif berupa ceramah, tanya jawab, dialog dan demonstrasi. Menurut Ulfah dan Saefuddin (2018) metode pembelajaran adalah suatu cara yang digunakan pendidik untuk mencapai tujuan pembelajaran. Metode pembelajaran juga dapat diartikan sebagai cara menyajikan materi untuk peserta didik agar tercapai tujuan pembelajaran. Kesimpulannya adalah metode pembelajaran berfungsi sebagai cara untuk mencapai tujuan pembelajaran. Kedudukan metode adalah sebagai salah satu komponen pembelajaran. Ada hal-hal yang perlu diperhatikan dalam pemilihan metode pembelajaran, antara lain tujuan yang ingin dicapai dalam pembelajaran, kemampuan dan latar belakang peserta didik, kemampuan dan latar belakang pendidik, keadaan proses belajar yang berlangsung, dan alat-alat atau sarana yang tersedia. Pengertian ceramah ditinjau dari bahasa adalah penuturan atau penerangan secara lisan oleh pendidik terhadap peserta didik. Pada metode ceramah terjadi interaksi antara pendidik dan peserta didik karena ada yang "berbicara" dan "mendengarkan" (Tambak, 2014).

Metode tanya jawab juga digunakan untuk menarik peserta didik dalam mengikuti kegiatan. Metode tanya jawab dilakukan dengan cara pendidik melemparkan pertanyaan ke peserta didik kemudian peserta didik dipersilahkan menjawab pertanyaan. Metode ini cukup efektif digunakan untuk menarik minat dan agar pembelajaran tidak monoton. Penelitian Ahmad \& Tambak (2017) tentang hubungan metode tanya jawab dengan minat belajar peserta didik pada mata pelajaran pendidikan agama islam menunjukkan hasilterdapat hubungan signifikan metode tanya jawab dengan minat belajar peserta didik pada mata pelajaran pendidikan agama islam.

Metode pembelajaran demonstrasi digunakan sebagai penguat pemahaman. Metode pembelajaran demonstrasi berdasarkan penelitian Fince, Ramadhan \& Gagaramusu (2015) tentang penerapan metode demonstrasi yang digunakan untuk meningkatkan hasil belajar siswa pada materi penyebab benda bergerak di kelas 1 SDN Dampala Kec. Bahodopi Kab. Morowali 
menunjukkan hasil ada perbaikan pembelajaran. Kesimpulan penelitian adalah metode demonstrasi dapat meningkatkan hasil belajar.

Mengukur keberhasilan edukasi diantaranya dengan evaluasi pembelajaran. Pada kegiatan pengabdian masyarakat ini juga dilakukan evaluasi pembelajaran. Evaluasi pembelajaran adalah gambaran kualitas hasil pembelajaran, yang menyangkut nilai atau arti. Gambaran kualitas dalam evaluasi pembelajaran merupakan konsekuensi hasil dari proses evaluasi yang dilakukan. Proses evaluasi tentu dilakukan secara sistematis dan berkelanjutan, serta terencana, sesuai dengan prosedur dan aturan, dan terus menerus di proses pembelajaran maupun akhir pembelaaran. Tujuan evaluasi adalah untuk menentukan kualitas dari peserta didik maupun pedidik terutama yang berhubungan dengan nilai dan arti (Arifin 2013 dalam Asrul, Ananda dan Rosnita 2014).

\subsection{Evaluasi}

Evaluasi pembelajaran menunjukkan peningkatan pemahaman peserta didik tentang pencegahan diabetes melitus sejak dini.Pemahaman ini sangat penting karena diabetes militus merupakan penyakit yang prosentasenya semakin meningkat dari tahun ke tahun. Menurut data Pusat Data dan Informasi Kementrian Kesehatan Republik Indonesia (Pusdatin Kemenkes RI), memperkirakan di Indonesia pada tahun 2030 ada sekitar 21,3 juta jiwa yang menderita DM. Peningkatan kasus tersebut juga disebabkan karena peningkatan kasus DM pada anak. Data dari Pusdatin Kemenkes RI (2018) mencatat kasus DM pada anak sejumlah 0.004\% pada anak yang berusia 5 - 14 tahun. Sedangkan menurut Ikatan Dokter Anak Indonesia (IDAI) (2017) pada anak usia 15-25 angka DM sebesar 0.05\% dari seluruh penduduk Indonesia (Ikatan Dokter Anak Indonesia (IDAI) (2017).

Berdasarkan penelitian Prasetyani dan Sodikin (2017) tentang analisis faktor yang berpengaruh terhadap kejadian DM tipe 2 menunjukkan hasil faktor obesitas merupakan faktor yang paling dominan berhubungan dengan kejadian DM tipe 2. Obesitas diartikan sebagai penumpukan lemak yang berlebihan akibat ketidakseimbangan asupan energi (energy intake) dengan energi yang digunakan (energy expenditure) dalam waktu relatif lama. Obesitas terjadi karena faktor pola makan yang kurang baik dan faktor aktifitas dan olahraga yang tidak optimal. Penelitian lain dengan tema faktor-faktor yang berhubungan dengan kejadian Diabetes Melitus tipe 2 oleh Kurniawaty \& Yanita (2016) menunjukkan hasil obesitas dan umur dapat meningkatkan risiko DM Tipe 2. Penelitian ini menyarankan agar kejadian obesitas perlu dilakukan dengan memperbaiki gaya hidup dan pola makan masyarakat. Perbaikan gaya hidup dilakukan dengan cara mengurangi stress, cukup tidur dan cukup aktifitas, sedangkan perbaikan pola makan dilakukan dengan makanan rendah karbohidrat, tidak banyak makanan instan dan mengandung banyak zat pengawet, pengental dan pemanis. Cara-cara pencegahan seperti tersebut diatas harus dilakukan sejak dini karena ada kecenderungan anak mengkonsumsi makanan yang tidak sehat.

DM tipe 2 pada anak biasanya terdiagnosis pada usia pubertas atau lebih tua. Gejala yang muncul sering disertai dengan kulit menjadi lebih gelap. Resistensi insulin atau masalah pada kerja insulin akan mengakibatkan area di beberapa kulit anak berubah menjadi lebih gelap, seperti ketiak dan leher (Direktorat Pencegahan Dan Pengendalian Penyakit Tidak Menular Kemenkes RI, 2018). Gejala yang muncul akibat DM adalah banyak makan, banyak minum, banyak kencing atau mengompol, penurunan berat badan secara drastis dalam 2-6 minggu sebelum terdiagnosis, kelelahan dan mudah marah. Banyak makan terjadi karena insulin tidak cukup untuk mengolah bahan makanan yang dimakan sehingga tidak bisa digunakan sel secara baik. Akibatnya sel akan terus merasa kekurangan makan. Banyak minum terjadi karena dehidrasi di tingkat sel. Banyak buang air kecil atau mengompol terjadi karena tubuh banyak minum. Penurunan berat badan secara drastis pada seseorang yang terdiagnosa DM terjadi karena ketidakmampuan tubuh dalam menyerap gula darah sehingga menyebabkan jaringan otot dan lemak menyusut. 
Penderita DM juga bisa mengalami masalah kegawatdaruratan. Tanda kedaruratan yang perlu diwaspadai antara lain dehidrasi, sesak napas, syok dan napas berbau keton (Direktorat Pencegahan dan Pengendalian Penyakit Tidak Menular Kemenkes RI, 2018). Gangguan sesak nafas dapat disebabkan karena kerusakan laten dari sel-sel tubuh yang berada di paru akibat angiopati atau neuropati. Keluhan dehidrasi dapat disebabkan karena hemokonsentrasi akibat tingginya kadar gula darah. Syok dapat terjadi jika dehidrasi tidak tertangani ataupun penurunan kesadaran karena gula darah yang tinggi yang berakibat pada suplai darah ke otak berkurang. Munculnya nafas berbau keton dapat disebabkan karena pembakaran lemak yang disebabkan ketidakmampuan tubuh mengolah makanan (metabolisme) dari bahan karbohidrat. Keadaan ini menjadi tanda ketoasidosis diabetikum.

Akibat dari DM sangatlah banyak. Semua pihak harus bekerjasama agar angka kejadian DM tidak semakin meningkat. Oleh karena itu kegiatan seperti pengabdian masyarakat yang telah dilakuan untuk pencegahan DM sejak dini pada anak merupakan hal yang positif. Kegiatan ini perlu dilakukan secara terus menerus dengan sasaran anak-anak sampai dewasa.

\section{Simpulan}

Simpulan dari pengabdian masyarakat adalah edukasi tentang pencegahan penyakit diabetes melitus sejak dini dapat meningkatkan pemahaman santri dan pengelola Pondok Pesantren Tahfidh Qur'an Al Fath Nyamplungsari Petarukan Pemalang Jawa Tengah. Saran untuk pengabdian masyarakat yang akan datang adalah dapat memberikan pelatihan berupa pelatihan tentang diet yang tepat untuk mencegah diabtes melitus sejak dini pada santri maupun pengelola.

\section{Persantunan}

Terimakasih penulis ucapkan pada pimpinan Universitas Muhammadiyah Pekajangan Pekalongan terutama Ketua Lembaga Penelitian dan Pengabdian Masyarakat yang telah memfasilitasi pelaksanaan pengabdian masyarakat. Terimakasih juga penulis haturkan untuk pengurus yayasan ASMA-88, pengelola dan ustadh ustadhah yang telah menjadi mitra dalam program pengabdian masyarakat ini.

\section{Referensi}

Amanah, S. (2007). Makna penyuluhan dan transformasi perilaku manusia. Jurnal penyuluhan, 3(1).

Ahmad, M. Y., \& Tambak, S. (2017). Hubungan Metode Tanya Jawab dengan Minat Belajar Peserta Didik pada Mata Pelajaran Pendidikan Agama Islam. Jurnal Pendidikan Agama Islam Al-Thariqah, 2(1), 89-110.

Asrul, Anada,R \& Rosnita (2014). Evaluasi pembelajaran. Bandung, Jawa Barat: Cita Pustaka Media

Direktorat Pencegahan Dan Pengendalian Penyakit Tidak Menular Kemenkes RI, (2018). Anak juga bisa diabetes. Diakses dari http://www.p2ptm.kemkes.go.id/kegiatan-p2ptm/dkijakarta/anak-juga-bisa-diabetes [10 Februari 2021]

Fince, F., Ramadhan, A., \& Gagaramusu, Y. (2015). Penerapan Metode Demonstrasi untuk Meningkatkan Hasil Belajar Siswa pada Materi Penyebab Benda Bergerak di Kelas 1 SDN Dampala Kec. Bahodopi Kab. Morowali. Jurnal Kreatif Online, 3(1).

Fajriyah, N. N., Aktifah, N., \& Mugiyanto, E. (2020). Paket Edukasi dan Deteksi Dini Meningkatkan Perilaku Perawatan Kaki Diabetisi di Puskesmas Kabupaten Pekalongan. Gaster, 18(1), 12-20.

Ikatan Dokter Anak Indonesia (IDAI). (2017). Waspadai Diabetes Melitus pada Anak. Diakses dari https://www.idai.or.id/artikel/klinik/keluhan-anak/waspadai-diabetes-melitus-padaanak [10 Februari 2021] 
Kurniawaty, E., \& Yanita, B. (2016). Faktor-faktor yang berhubungan dengan kejadian Diabetes Melitus tipe II. Jurnal Majority, 5(2), 27-31.

Miftah, M. (2013). Fungsi dan peran media pembelajaran sebagai upaya peningkatan kemampuan belajar siswa. Jurnal KWANGSAN, 1(2), 95-105.

Muliasari, H. Hamdin, C.D, Ananto, A.D ,\& Ihsan. M. (2019). Edukasi dan deteksi dini diabetes melitus sebagai upaya mengurangi prevalensi dan resiko penyakit degenerative. Jurnal Pendidikan dan Pengabdian Masyarakat, 2(1), 76-79.

Pusat Data dan Informasi Kementrian Kesehatan Republik Indonesia. (2018). Hari Diabetess Sedunia tahun 2018. Diakses dari https://pusdatin.kemkes.go.id_[10 Februari 2021]

Prasetyani, D., \& Sodikin, S. (2017). Analisis Faktor Yang Mempengaruhi Kejadian Dm Melitus (Dm) Tipe 2. Jurnal Kesehatan Al-Irsyad, 1-9.

Rosyid, F.N. Hudiawati, D. \& Kristinawati, B. (2019). Peningkatan pengetahuan dan upaya pencegahan diabetes melitus melalui pendidikan kesehatan. Jurnal Pengabdian kepada Masyarakat, 7(2), $91-94$.

Saryanti, D \& Nugraheni D. (2019). Peningkatan pengetahuan masyarakat tentang penyakit diabetes melitus. Jurnal Pengabdian dan Pemberdayaan Masyarakat., 3(1), 111-116.

Sari, I. P. T. P. (2013). Pendidikan kesehatan sekolah sebagai proses perubahan perilaku siswa. Jurnal Pendidikan Jasmani Indonesia, 9(2).

Tambak, S. (2014). Metode Ceramah: Konsep dan Aplikasi dalam Pembelajaran Pendidikan Agama Islam. Jurnal Tarbiyah, 21(2).

Ulfah, M \& Saefuddin. (2018). Terampil memilih dan menggunakan metode pembelajaran. SUHUF, 30(1), 35-56.

Wahyuni, K. Prayitno, A.A \& Yosi, W. (2019). Efektivitas Edukasi Pasien Diabetes Melitus Tipe 2 Terhadap Pengetahuan dan Kontrol Glikemik Rawat Jalan di RS Anwar Medika. Jurnal Pharmascience; 6(1), 1-9.

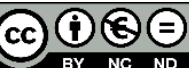

(C) 2022 by the authors. Submitted for possible open access publication under the terms and conditions of the Creative Commons Attribution (CC-BY-NC-ND) license (http://creativecommons.org/licenses/by/4.0/). 